\title{
Impaired $\beta$-adrenergically mediated lipolysis in skeletal muscle of obese subjects
}

\author{
E. E. Blaak ${ }^{1}$ S. L. Schiffelers ${ }^{1}$ W. H. Saris ${ }^{1}$ M. Mensink ${ }^{1}$ M. E. Kooi ${ }^{2}$ \\ ${ }^{1}$ Department of Human Biology, Nutrition Research Centre, Maastricht University, Maastricht, The Netherlands \\ 2 Department of Radiology, University Hospital Maastricht, The Netherlands
}

\section{Abstract}

Aims/hypothesis. The aim of this study was to investigate whether the $\beta_{2}$-adrenergically mediated increase in interstitial glycerol concentrations (used as an indicator of local lipolysis) was impaired in the skeletal muscle (the gastrocnemius muscle) of obese subjects compared with in that of lean subjects, and whether any differences in muscle lipolysis were related to differences in intramyocellular muscle triglyceride content.

Methods. A microdialysis experiment was performed in the gastrocnemius muscle of eight lean and eight obese men (body fat $22.1 \pm 1.6 \%$ vs $32.7 \pm 1.6 \%$ respectively). After determining baseline extracellular glycerol concentrations, the probe was perfused with increasing concentrations of the $\beta_{2}$-agonist, salbutamol (doses of 1,10 and $100 \mu \mathrm{mol} / \mathrm{l}$ for 45 -min periods). Local blood flow was determined using the ethanol dilution technique. Intramyocellular lipid content was determined using ${ }^{1} \mathrm{H}$-magnetic resonance spectroscopy.

Results. Compared with that in lean subjects, the $\beta_{2^{-}}$ adrenergically mediated increase in glycerol concentrations (absolute and percentage change) was blunted in obese subjects (at $100 \mu \mathrm{mol} / \mathrm{l}$ of salbutamol, percentage change $12.0 \pm 12 \%$ vs $48 \pm 12 \%, p<0.05)$. The decrease in ethanol out : in ratio was less pronounced in the obese individuals $(p<0.05)$, indicating a diminished increase in local muscle blood flow. Intramyocellular lipid content was comparable in both groups. Conclusions/interpretation. The capacity to increase skeletal interstitial glycerol concentrations during direct $\beta_{2}$-adrenergic stimulation is impaired in obese subjects with normal intramyocellular concentrations, suggesting that this may be an early event in the process of triglyceride accumulation.

Keywords $\beta$-Adrenergic stimulation - Intramyocellular lipids $\cdot$ Lipolysis $\cdot$ Obesity $\cdot$ Skeletal muscle
Received: 10 December 2003 / Accepted: 19 April 2004

Published online: 28 July 2004

(C) Springer-Verlag 2004

\section{E. E. Blaak $(\bowtie)$}

Department of Human Biology, Nutrition Research Centre, Maastricht University, P.O. Box 616, 6200 MD Maastricht, The Netherlands

E-mail: E.Blaak@HB.Unimaas.nl

Tel.: +31-433881639, Fax: +31-433670976

Abbreviations: EMCL, extramyocellular lipids .

IMCL, intramyocellular lipids · MRS, magnetic resonance spectroscopy

\section{Introduction}

Obesity is associated with disturbances in skeletal muscle fat metabolism. The uptake and/or oxidation of fatty acids has been shown to be diminished in the skeletal muscle of obese subjects under post-absorptive conditions [1] and during $\beta$-adrenergic stimulation [2], which may be a characteristic of visceral obesity [1]. Oil-red $\mathrm{O}$ staining of muscle biopsies [3, 4] and magnetic resonance imaging [5] have shown that skeletal muscle triglyceride content is increased in obese subjects, although this has not been confirmed in all studies [6]. A strong link between increased muscle triglyceride stores and skeletal muscle insulin resistance has been shown in normal-weight, non-dia- 
betic subjects [7], in insulin-resistant obese Pima Indians [8] and in lean offspring of Type 2 diabetic parents $[9,10]$. Recent studies have indicated that the accumulation of lipid intermediates (such as long-chain fatty acid acyl CoA and diacylglycerol) may be the direct link with skeletal muscle insulin resistance, rather than increased intramuscular triglyceride storage in itself, through interference with insulin signalling $[11,12]$.

An imbalance between fatty acid uptake and fatty acid oxidation/esterification may predispose obese subjects towards the development of increased triglyceride stores. Alternatively, disturbances in the regulation of intramuscular lipolysis may contribute to increased triglyceride storage. In rat and human skeletal muscle, a hormone-sensitive lipase very similar to the adipose tissue hormone-sensitive lipase has been identified [13] which can be stimulated by epinephrine and muscle contractions [14]. Interstitial glycerol concentrations, as measured by microdialysis, have been studied to obtain further insight into the regulation of local muscle lipolysis. It has been shown that skeletal muscle lipolysis is stimulated by catecholamines through the $\beta_{2}$-adrenergic receptor subtype alone [15], and is inhibited by insulin [16]. A recent study showed that net muscle glycerol release was comparable in non-obese and obese subjects under postabsorptive conditions and after glucose ingestion [17]. To date, our knowledge on differences in the regulation of muscle lipolysis between lean and obese subjects is limited.

The aim of our study was to investigate whether the $\beta_{2}$-adrenergically mediated increase in interstitial glycerol (used as indicator of local lipolysis), as measured by microdialysis, was impaired in the skeletal muscle (gastrocnemius muscle) of obese subjects compared with in that of lean subjects. We also aimed to ascertain whether any differences in the regulation of interstitial glycerol concentrations between lean and obese individuals relate to differences in the content of intramyocellular lipids (IMCL) by measuring triglyceride levels in the gastrocnemius muscle using magnetic resonance spectroscopy (MRS).

\section{Subjects and methods}

\section{Subjects}

Eight obese and eight lean male volunteers participated in this study. Body density was determined by hydrostatic weighing with simultaneous lung volume measurement (Volugraph 2000, Mijnhardt, Bunnik, The Netherlands). Body composition was calculated according to the equation of Siri [18]. All subjects were in good health as assessed by medical history and physical examination. Furthermore, neither obese nor lean subjects spent more than $2 \mathrm{~h}$ per week participating in organised sports activities. The study protocol was reviewed and approved by the Ethics Committee of Maastricht University and all subjects gave informed consent before participating in the study.

\section{Microdialysis experiments}

All subjects were studied in the supine position after an overnight fast. They were transported to the laboratory either by car or by bus. On arrival, a microdialysis probe (CMA 60, CMA Microdialysis, Solna, Sweden) was inserted percutaneously with a steel guide cannula into the medial portion of the gastrocnemius muscle after anaesthetising the skin and muscle fascia with lidocaine. The probe consisted of dialysis tubing $\left(30 \times 0.6 \mathrm{~mm}, 20 \mathrm{M}_{\mathrm{r}}\right.$ cut-off) glued to the end of a double-lumen polyurethane cannula. The perfusion solvent entered the probe through the inner cannula, passed down to the tip of the probe, streamed upwards in the space between the inner cannula and the outer dialysis membrane and left the probe through the outer cannula via a side arm, from which it was collected.

Microdialysis protocol. After insertion, the probe was perfused with Ringer solution ( $147 \mathrm{mmol} / \mathrm{l}$ sodium, $4 \mathrm{mmol} / \mathrm{l}$ potassium, $2.25 \mathrm{mmol} / \mathrm{l}$ calcium and $156 \mathrm{mmol} / \mathrm{l}$ chloride) supplemented with $50 \mathrm{mmol} / \mathrm{l}$ ethanol at a flow rate of $0.5 \mu \mathrm{l} / \mathrm{min}$ for $90 \mathrm{~min}$ before the start of the experiment. During the first part of the experiment, the real interstitial glycerol concentration was determined using the zero flow method [19]. Microdialysate was collected in two 20 -min fractions at a flow rate of $0.5 \mu \mathrm{l} / \mathrm{min}$ and in three 10-min fractions at flow rates of $1,2.5$ and $5 \mu \mathrm{l} / \mathrm{min}$ respectively. During the second part of the experiment, probes were perfused with increasing concentrations of the selective $\beta_{2}$-adrenoceptor agonist, salbutamol, at a flow rate of $5 \mu \mathrm{l} / \mathrm{min}$. During each agonist-infusion period, one 15 -min dialysate collection fraction was followed by three 10 -min fractions. Dialysate glycerol concentrations were measured in all samples collected at flow rates of $0.5,1.0$ and $2.5 \mu \mathrm{l} / \mathrm{min}$. Both dialysate glycerol and ethanol concentrations were measured in all samples collected at a flow rate of $5 \mu \mathrm{l} / \mathrm{min}$. Ethanol concentrations were determined in both the ingoing and the outgoing perfusion solvent to assess the ethanol out : in ratio (as an indicator of nutritive blood flow) using the ethanol escape technique as described previously [20].

Zero flow method. During the first part of the experiment, the absolute interstitial glycerol concentration was determined using the zero flow method. The probe was perfused at a flow rate of $0.5 \mu \mathrm{l} / \mathrm{min}$ for $40 \mathrm{~min}$ and at consecutive flow rates of $1,2.5$ and $5 \mu \mathrm{l} / \mathrm{min}$ for $30 \mathrm{~min}$. Dialysate glycerol concentrations were $1_{n}$-transformed and plotted against perfusion rates. Linear regression analysis was used to calculate the glycerol concentration at a flow rate of zero, corresponding to the real interstitial glycerol concentration. The ratio between the dialysate glycerol concentration at $5 \mu \mathrm{l} / \mathrm{min}$ and the calculated interstitial glycerol concentration represented the in vivo recovery rate of the probe.

Perfusion with a $\beta 2$-adrenoceptor agonist. During the second part of the experiment, the probe was perfused with the selective $\beta_{2}$-adrenoceptor agonist, salbutamol, and changes in interstitial glycerol and ethanol were determined. The calibration period with a flow rate of $5 \mu \mathrm{l} / \mathrm{min}$ was used as the baseline measurement. The probe was subsequently perfused with 1,10 and $100 \mu \mathrm{mol} / \mathrm{l}$ of salbutamol to stimulate $\beta_{2}$-adrenoceptors. Each dose of agonist was administered for $45 \mathrm{~min}$ at a flow rate of $5 \mu \mathrm{l} / \mathrm{min}$. 
Assessment of intramyocellular lipid content

The IMCL content of the gastrocnemius muscle was quantified using ${ }^{1} \mathrm{H}-\mathrm{MRS}$ in a $1.5-\mathrm{T}$ whole-body scanner (Philips Intera, release 8.1.2; Philips Medical Systems, Best, The Netherlands). Subjects refrained from exhaustive physical exercise the day before the measurements were taken. The lower leg was positioned in a quadrature knee coil. Transversal scout images were made with a T2-weighted turbo spin echo sequence. Voxel positions avoided adipose tissue depots as much as possible. The image-guided, localised ${ }^{1} \mathrm{H}-\mathrm{MRS}$ spectra from the regions of interest were acquired using a point-resolved spectroscopy sequence (PRESS; repetition time $3000 \mathrm{~ms}$, echo time $25 \mathrm{~ms}, 16$ phase cycles, 1024 data points over $1000 \mathrm{~Hz}$ spectral width with 128 averages) with a voxel volume of $12 \times 11 \times$ $18 \mathrm{~mm}^{3}$. The water signal was suppressed using frequencyselective pre-pulses. The unsuppressed water signal was used as a reference signal. Fine shimming of the voxel was performed to optimise the homogeneity of the magnetic field within the region of interest.

The spectra were fitted in the time domain using a sophisticated non-linear least-squares algorithm (AMARES [21]) in the jMRUI software package (http://www.mrui.uab.es/mrui) [22]. Three peaks were fitted for both IMCL and extramyocellular lipid (EMCL) as described previously [23]. Briefly, prior knowledge of the relative peak positions and area ratios was used as a constraint in order to increase the accuracy and reliability of the fitting procedure. The signals were corrected for $\mathrm{T} 1$ and $\mathrm{T} 2$ relaxation using the $\mathrm{T} 1$ and $\mathrm{T} 2$ relaxation times as determined by Schick et al. [24]. The corrected area of the $\mathrm{CH}_{2}$ peak of IMCL was expressed relative to the corrected area of

Fig. 1. A typical ${ }^{1} \mathrm{H}$-magnetic resonance spectrum of the gastrocnemius muscle in a lean subject (a) and an obese subject (b). EMCL, $\mathrm{CH}_{2}$ peak of extramyocellular lipid; IMCL, $\mathrm{CH}_{2}$ peak of intramyocellular lipid; tCr, total creatine; TMA, trimethylammonium compounds; $v$, relative resonance frequency

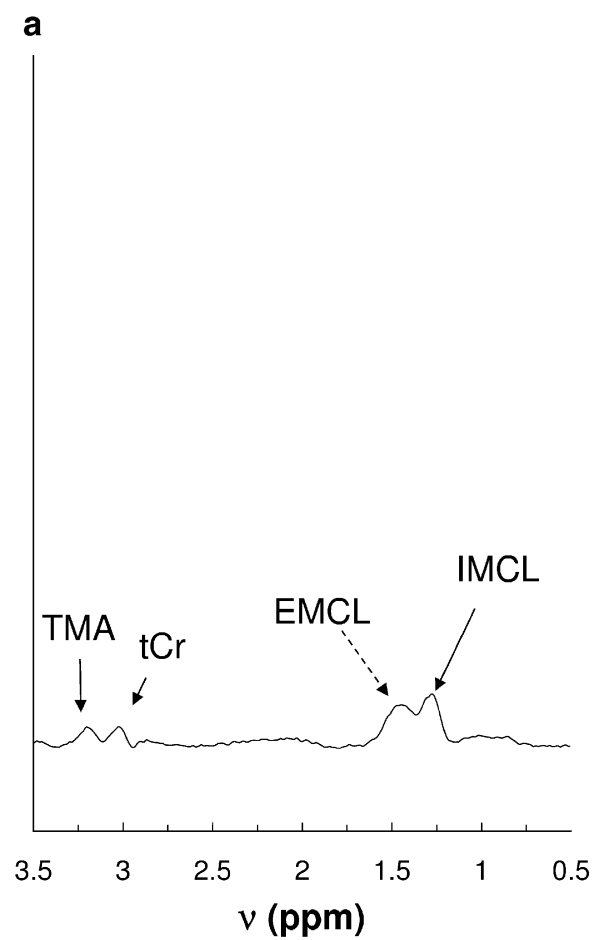

the water peak. The reproducibility of the IMCL measurement (within-voxel coefficient of variation) was determined in two subjects for three different voxels per subject by performing two subsequent measurements with the subjects leaving the magnet between measurements. The voxels were placed at the same positions for the repeat measurements. The variability of the IMCL content (between-voxel coefficient of variation) was calculated as the variation between different voxel positions in the same subject $(n=12)$.

Analytical methods

Glycerol and ethanol concentrations in the dialysate from the microdialysis experiments were determined on a Cobas Fara centrifugal analyser (Roche Diagnostica, Basel, Switzerland). Glycerol concentration was measured fluorimetrically using a standard glycerol kit (Boehringer, Mannheim, Germany), with concentrations of NADH, enzymes and buffer adjusted to achieve accurate fluorimetric detection. The intra-assay coefficient of variation of this assay was $3.4 \%$ and the inter-assay coefficient of variation was $7.1 \%$. Ethanol concentration was measured spectrophotometrically at $340 \mathrm{~nm}$ using a standard ethanol kit (176290, Boehringer).

\section{Statistical methods}

All data are presented as means \pm SEM. IMCL and EMCL content were compared using an unpaired Student's $t$ test. The effect of $\beta_{2}$-adrenergic stimulation between groups was analysed with two-way repeated measurements ANOVA. The relationship between IMCL and interstitial glycerol concentrations was analysed by means of regression analysis. A $p$ value of less than 0.05 was regarded as statistically significant.

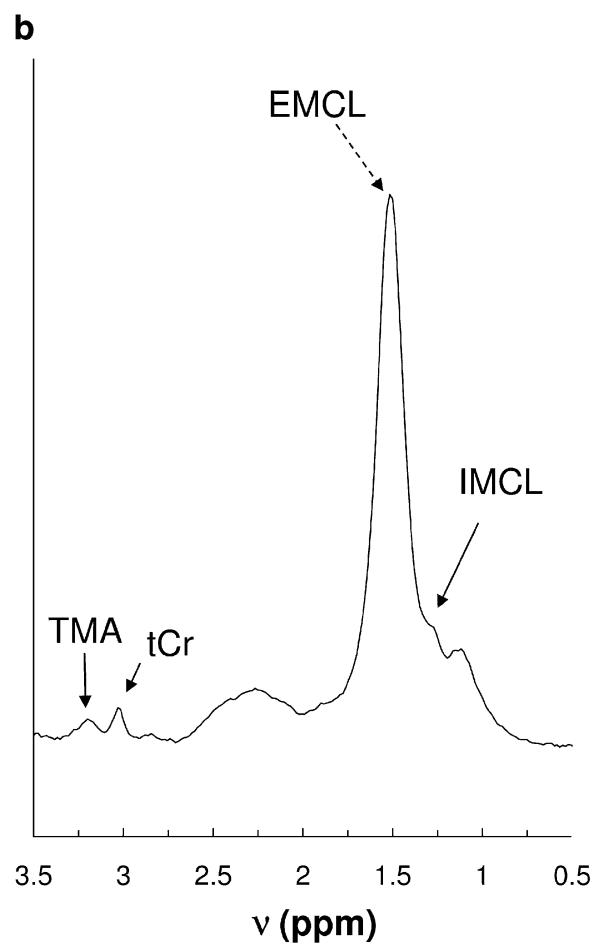


Table 1. Physical characteristics of the subjects

\begin{tabular}{lcc}
\hline & Lean subjects $(n=8)$ & Obese subjects $(n=8)$ \\
\hline Age (years) & $56.4 \pm 1.7$ & $54.5 \pm 1.7$ \\
Weight $(\mathrm{kg})$ & $73.3 \pm 2.2$ & $99.1 \pm 2.1^{\mathrm{b}}$ \\
Height $(\mathrm{m})$ & $1.74 \pm 0.02$ & $1.77 \pm 0.02$ \\
BMI $\left(\mathrm{kg} / \mathrm{m}^{2}\right)$ & $24.1 \pm 0.3$ & $31.6 \pm 0.7^{\mathrm{b}}$ \\
Body fat $(\%)$ & $21.8 \pm 1.4$ & $32.1 \pm 1.5^{\mathrm{b}}$ \\
WHR & $0.94 \pm 0.03$ & $1.03 \pm 0.02^{\mathrm{a}}$ \\
IMCL $(\%)^{\mathrm{c}}$ & $0.55 \pm 0.12^{\mathrm{d}}$ & $0.49 \pm 0.06$ \\
\hline
\end{tabular}

Values are means \pm SEM. ${ }^{\mathrm{a}} p<0.05 ;{ }^{\mathrm{b}} p<0.001 ;{ }^{\mathrm{c}}$ expressed relative to water peak; ${ }^{\mathrm{d}} n=7$

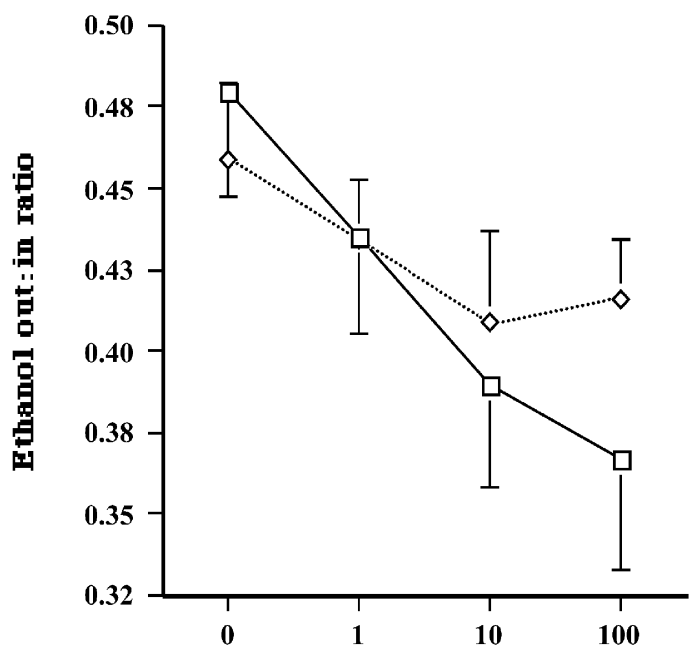

Salbutamol concentration $(\mu \mathrm{mol} / \mathrm{l})$

Fig. 2. Effect of salbutamol ( $\beta_{2}$-adrenoceptor agonist) on the ethanol out : in ratio in skeletal muscle (gastrocnemius muscle) of obese subjects (open diamonds) and lean subjects (open squares). Date are means \pm SEM. Two-way repeated measures ANOVA: repeated measures $p<0.001$; group $p<0.05$

\section{Results}

Subjects and muscle lipids. The characteristics of the subjects are presented in Table 1. By definition, body fat and BMI were higher in the obese subjects. MRS spectra were obtained in seven lean and eight obese subjects. Representative ${ }^{1} \mathrm{H}-\mathrm{MRS}$ spectra for lean and obese subjects are shown in Figure 1.The within-voxel coefficient of variation in two subjects (with BMIs of 25.2 and 30.7 ) was $17.7 \pm 13.3 \%$ (mean \pm SD) for IMCL. The between-voxel coefficient of variation $(n=12)$ for IMCL was $39 \pm 26 \%(34 \pm 22 \%$ in lean and $44 \pm 30 \%$ in obese subjects). There were no differences in the content of IMCL, expressed as percentage of water resonance, between lean and obese subjects.

Local blood flow and local lipolysis. Basal values for the ethanol out : in ratio tended to be lower in the

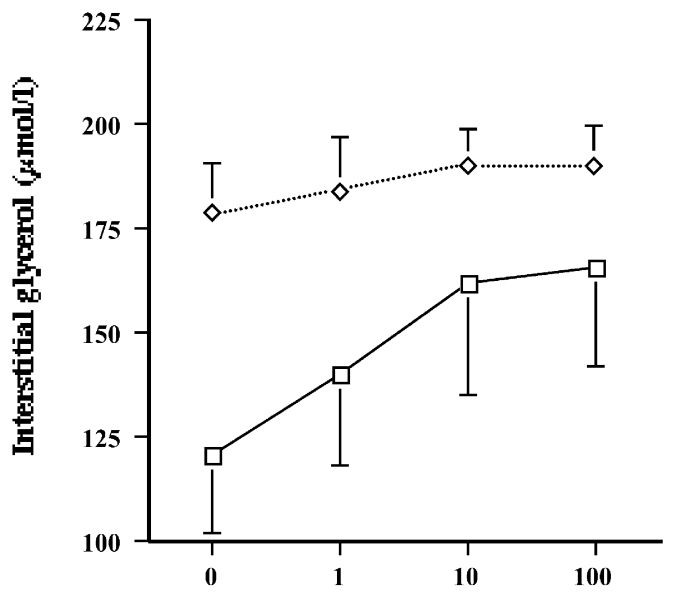

Salbutamol concentration $(\mu \mathrm{mol} / \mathrm{l})$

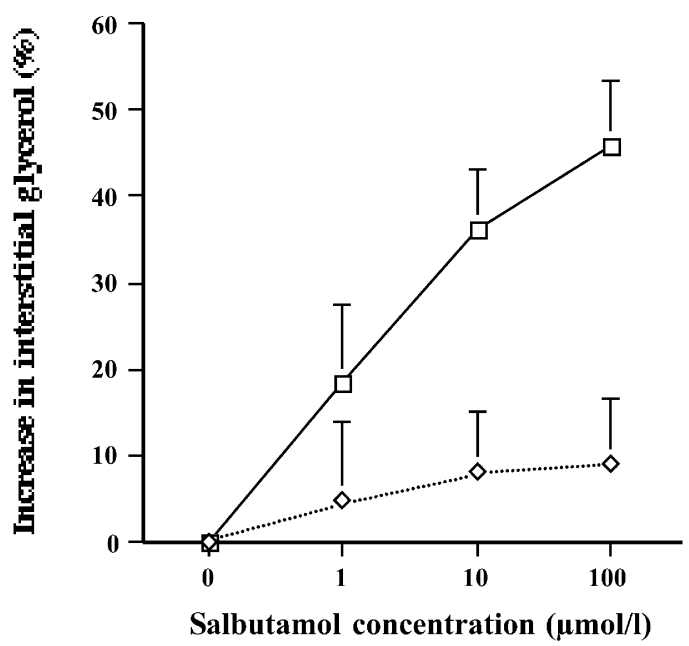

Fig. 3. Effect of salbutamol ( $\beta_{2}$-adrenoceptor agonist) on interstitial glycerol concentration (a) and percentage increase in glycerol (b) in skeletal muscle (gastrocnemius muscle) of obese subjects (open diamonds) and lean subjects (open squares). Date are means \pm SEM. Two-way repeated measures ANOVA: repeated measures $p<0.001$; group $p<0.05$

obese subjects, but differences between groups did not reach statistical significance (Fig. 2). In both groups there was a significant decrease $(p<0.001)$ in the ethanol out : in ratio during the infusion of an increasing dose of salbutamol, indicative of an increased local blood flow. This decrease in ratio (increase in blood flow) was significantly more pronounced in lean subjects $(p<0.05)$.

Probe recovery, calculated as (measured/real interstitial glycerol $) \times 100$, was $29.3 \pm 5.2 \%$ (mean $\pm \mathrm{SD}$ ), with no difference observed between lean and obese subjects. Compared with lean subjects, basal interstitial glycerol concentrations were significantly higher in obese individuals $(179 \pm 12$ vs $121 \pm 20 \mu \mathrm{mol} / 1, p<0.05)$. Both groups exhibited a dose-dependent increase in interstitial glycerol concentrations during the infusion of increasing doses of the $\beta_{2}$-agonist, salbutamol $(p<0.001$; Fig. 3$)$. The increase in interstitial glycerol 
during perfusion with the $\beta_{2}$-agonist was significantly blunted in obese subjects as compared with lean subjects, both when expressed as an absolute increase $(p<0.05)$ and as a percentage increase $(100 \mu \mathrm{mol} / \mathrm{l} \mathrm{sal-}$ butamol; $12.0 \pm 12 \%$ vs $48 \pm 12 \%, p<0.05)$. IMCL content did not correlate with percentage body fat or basal or salbutamol-induced $(100 \mu \mathrm{mol} / \mathrm{l})$ glycerol concentrations.

\section{Discussion}

In recent years, several investigations have focused on the relationship between intramyocellular triglyceride stores and insulin resistance in non-diabetic individuals [7]. Enlargement of the intramyocellular triacylglycerol stores has been proposed to be of importance in the aetiology of Type 2 diabetes mellitus, possibly reflecting the effect of the concomitantly increased diacylglycerol and long-chain fatty acid concentrations on insulin signal transduction [12]. The present study aimed to investigate: (i) the regulation of interstitial glycerol concentrations as a reflection of local lipolysis in the gastrocnemius muscle of obese subjects; and (ii) the IMCL content in the same muscle using ${ }^{1} \mathrm{H}-\mathrm{MRS}$.

The main findings of the present study were that the $\beta_{2}$-adrenergically mediated increases in interstitial glycerol concentrations and local blood flow were significantly blunted in obese subjects, suggesting that regulation of muscle lipolysis is disturbed in these individuals. Furthermore, IMCL content was similar in both groups of subjects.

Interstitial glycerol concentrations and lipolysis. Several methodological issues can be raised with respect to the present findings.

Firstly, since the blunted lipolytic response in obese individuals was not accompanied by an increase in IMCL stores, the question arises of whether the (changes in) interstitial glycerol merely reflect the metabolism of the extramyocellular fat stores. However, it has been shown in several studies that interstitial glycerol is regulated differently (by both insulin and $\beta$-adrenergic stimulation) in adipose tissue as compared with muscle in both lean and obese subjects [16, 25]. In addition, inhibition of lipolysis in adipose tissue and skeletal muscle is mediated by separate and specific phosphodiesterase subtypes [26]. In a previous study of the same subjects, the lipolytic and nutritive blood-flow response to $\beta_{1^{-}}, \beta_{2^{-}}$and non-selective $\beta$-adrenergic stimulation in adipose tissue was comparable in lean and obese subjects [27], suggesting that also the adipocytes between muscle bundles (EMCL) may respond similarly in the two groups. Thus, although we cannot exclude that EMCL could have contributed to the interstitial glycerol concentrations to some extent (particularly in the obese), our previous finding suggests that the blunted $\beta_{2}$-adrenergically mediated lipolytic response may be a characteristic of the IMCL stores rather than of the EMCL. As lean and obese subjects have similar amounts of IMCL, it is tempting to speculate that obese individuals have an impaired capacity to increase the lipolysis of IMCL before the accumulation of these lipids occurs. Thus, an inability to regulate muscle lipolysis may be an early event in the process leading to increased lipid deposition within muscle in obesity. It was recently reported that obese subjects are able to maintain normal IMCL stores in the presence of increased lipid oxidation [6]. The previously reported reduced fatty acid uptake and/or fat oxidation in muscle of abdominally obese subjects $[1,2,28,29]$ may be a characteristic of the more obese subject [30], suggesting that IMCL accumulation may only occur in the presence of a reduced capacity to oxidise fat.

A second methodological issue that can be raised is that, in the present study, interstitial glycerol has been used as a measure of lipolysis. There are indications that skeletal muscle may take up glycerol and may exhibit significant glycerol kinase activity [31]. This suggests that interstitial glycerol may not reflect the overall rate of lipolysis, but may instead be the net result of triglyceride and glycerol metabolism in muscle tissue and thus reflect glycerol turnover [32]. On the basis of the above findings, we cannot exclude the possibility that the blunted increase in interstitial glycerol may also be (partly) due to differences in glycerol metabolism, i.e. incorporation into triglyceride stores [31] and/or uptake from plasma.

Thirdly, there may be marked heterogeneity in lipolysis between different muscle groups [33]. Thus, further studies are necessary to determine whether this blunted capacity to stimulate muscle lipolysis extends to other muscle groups.

Intramyocellular lipids and obesity. Results on the relationship between IMCL and increased adiposity are inconsistent. Pan et al. [8] showed that muscle triacylglycerol content (as determined by biochemical analysis) was not related to any measure of adiposity (i.e. percentage body fat, BMI or WHR). Two studies have shown a higher than normal IMCL content in the lean, insulin-resistant offspring of Type 2 diabetic subjects $[9,16]$ indicating that the relationship between IMCL and insulin sensitivity may be independent of body composition. Conversely, several studies have demonstrated that obese subjects have a higher IMCL content than lean subjects using the oil-red $\mathrm{O}$ technique $[3,4]$ or ${ }^{1} \mathrm{H}-\mathrm{MRS}$ (in obese adolescents) [5]. In the present study, IMCL content was not significantly different between lean and obese subjects. The reproducibility of IMCL determination by our ${ }^{1} \mathrm{H}-\mathrm{MRS}$ measurement (within-voxel variation) was $17.7 \%$ in obese subjects, which is higher than that reported $(4-12 \%)$ for measurements in the calf muscle in lean 
subjects [34]. The variability (between-voxel variation) was also higher in obese subjects than in lean subjects (44\% vs 34\%), and higher than the values reported previously by Hwang et al. (13-20\% in lean young males) [35]. Based on these results, it can be estimated that with the present number of subjects, a difference in IMCL of at least $25 \%$ was required for detection using this method, indicating that we might have failed to identify slight differences between groups. As already indicated above, part of the discrepancy between different studies on obesity and IMCL accumulation in muscle may be related to differences in the type of muscle studied (with concomitant variation in lipolytic activity, muscle fibre type and glycolytic and oxidative enzyme capacity) [35], the degree of obesity [30] or body fat distribution [1].

Local blood flow. The capacity to stimulate nutritive muscle blood flow seems to be blunted in obese subjects. This is consistent with findings indicating a tendency towards a diminished blood-flow response in the forearm muscle of obese subjects during i.v. $\beta$-adrenergic stimulation [2] and insulin stimulation [36]. This attenuated blood-flow response implies that differences between the $\beta_{2}$-adrenergically mediated increase in interstitial glycerol between lean and obese subjects would be even higher if changes in blood flow were taken into account. In addition to the diminished transport of metabolites from the muscle, this reduced response may play a role in the diminished delivery of nutrients to the muscle, and has been hypothesised to be of importance in skeletal muscle insulin resistance.

In conclusion, the present study demonstrates that obese subjects have a capacity to increase interstitial glycerol concentrations during direct $\beta_{2}$-adrenergic stimulation. As IMCL content was comparable in lean and obese subjects, it can be speculated that a limited ability to regulate muscle lipolysis is present before the accumulation of lipids occurs within the muscle of obese subjects.

\section{References}

1. Colberg SR, Simoneau JA, Thaete FL, Kelley DE (1995) Skeletal muscle utilization of free fatty acids in women with visceral obesity. J Clin Invest 95:1846-1853

2. Blaak EE, Van Baak MA, Kemerink GJ, Pakbiers MT, Heidendal GA, Saris WH (1994) Beta-adrenergic stimulation of energy expenditure and forearm skeletal muscle metabolism in lean and obese men. Am J Physiol 267:E306-E315

3. He J, Watkins S, Kelley DE (2001) Skeletal muscle lipid content and oxidative enzyme activity in relation to muscle fiber type in type 2 diabetes and obesity. Diabetes 50:817-823

4. Malenfant P, Joanisse DR, Theriault R, Goodpaster BH, Kelley DE Simoneau JA (2001) Fat content in individual muscle fibers of lean and obese subjects. Int J Obes Relat Metab Disord 25:1316-1321
5. Sinha R, Dufour S, Petersen KF et al. (2002) Assessment of skeletal muscle triglyceride content by (1)H nuclear magnetic resonance spectroscopy in lean and obese adolescents: relationships to insulin sensitivity, total body fat, and central adiposity. Diabetes 51:1022-1027

6. Perseghin G, Scifo P, Danna M et al. (2002) Normal insulin sensitivity and IMCL content in overweight humans are associated with higher fasting lipid oxidation. Am J Physiol Endocrinol Metab 283:E556-E564

7. Krssak M, Falk Petersen K, Dresner A et al. (1999) Intramyocellular lipid concentrations are correlated with insulin sensitivity in humans: a $1 \mathrm{H} \mathrm{NMR} \mathrm{spectroscopy} \mathrm{study.}$ Diabetologia 42:113-116

8. Pan DA, Lillioja S, Kriketos AD et al. (1997) Skeletal muscle triglyceride levels are inversely related to insulin action. Diabetes 46:983-988

9. Perseghin G, Scifo P, De Cobelli F et al. (1999) Intramyocellular triglyceride content is a determinant of in vivo insulin resistance in humans: a $1 \mathrm{H}-13 \mathrm{C}$ nuclear magnetic resonance spectroscopy assessment in offspring of type 2 diabetic parents. Diabetes 48:1600-1606

10. Jacob S, Machann J, Rett K et al. (1999) Association of increased intramyocellular lipid content with insulin resistance in lean nondiabetic offspring of type 2 diabetic subjects. Diabetes 48:1113-1119

11. Schmitz-Peiffer C (2000) Signalling aspects of insulin resistance in skeletal muscle: mechanisms induced by lipid oversupply. Cell Signal 12:583-594

12. Ellis BA, Poynten A, Lowy AJ et al. (2000) Long-chain acyl-CoA esters as indicators of lipid metabolism and insulin sensitivity in rat and human muscle. Am J Physiol Endocrinol Metab 279:E554-E560

13. Langfort J, Ploug T, Ihlemann J et al. (1998) Hormonesensitive lipase (HSL) expression and regulation in skeletal muscle. Adv Exp Med Biol 441:219-228

14. Langfort J, Ploug T, Ihlemann J, Saldo M, Holm C, Galbo $\mathrm{H}$ (1999) Expression of hormone-sensitive lipase and its regulation by adrenaline in skeletal muscle. Biochem $\mathrm{J}$ 340:459-465

15. Hagstrom-Toft E, Enoksson S, Moberg E, Bolinder J, Arner P (1998) beta-Adrenergic regulation of lipolysis and blood flow in human skeletal muscle in vivo. Am J Physiol 275: E909-E916

16. Stumvoll M, Jacob S, Wahl HG et al. (2000) Suppression of systemic, intramuscular, and subcutaneous adipose tissue lipolysis by insulin in humans. J Clin Endocrinol Metab 85:3740-3745

17. Bolinder J, Kerckhoffs DA, Moberg E, Hagstrom-Toft E, Arner P (2000) Rates of skeletal muscle and adipose tissue glycerol release in nonobese and obese subjects. Diabetes 49:797-802

18. Siri W (1956) The gross composition of the body. Adv Exp Med Biol 4:239-280

19. Stahle L, Segersvard S, Ungerstedt U (1991) A comparison between three methods for estimation of extracellular concentrations of exogenous and endogenous compounds by microdialysis. J Pharmacol Methods 25:41-52

20. Arner P, Bulow J (1993) Assessment of adipose tissue metabolism in man: comparison of Fick and microdialysis techniques. Clin Sci (Lond) 85:247-256

21. Vanhamme L, Boogaart A van den, Van Huffel S (1997) Improved method for accurate and efficient quantification of MRS data with use of prior knowledge. J Magn Reson 129:35-43

22. Naressi A, Couturier C, Devos JM et al. (2001) Java-based graphical user interface for the MRUI quantitation package. MAGMA 12:141-152 
23. Schrauwen-Hinderling VB, Schrauwen P, Hesselink MK et al. (2003) The increase in intramyocellular lipid content is a very early response to training. J Clin Endocrinol Metab 88:1610-1616

24. Schick F, Eismann B, Jung WI, Bongers H, Bunse M, Lutz O (1993) Comparison of localized proton NMR signals of skeletal muscle and fat tissue in vivo: two lipid compartments in muscle tissue. Magn Reson Med 29:158-167

25. Hagstrom-Toft E, Thorne A, Reynisdottir S et al. (2001) Evidence for a major role of skeletal muscle lipolysis in the regulation of lipid oxidation during caloric restriction in vivo. Diabetes 50:1604-1611

26. Enoksson S, Degerman E, Hagstrom-Toft E, Large V, Arner P (1998) Various phosphodiesterase subtypes mediate the in vivo antilipolytic effect of insulin on adipose tissue and skeletal muscle in man. Diabetologia 41:560-568

27. Schiffelers SL, Akkermans JA, Saris WH, Blaak EE (2003) Lipolytic and nutritive blood flow response to beta-adrenoceptor stimulation in situ in subcutaneous abdominal adipose tissue in obese men. Int J Obes Relat Metab Disord 27:227-231

28. Kelley DE, Mandarino LJ (2000) Fuel selection in human skeletal muscle in insulin resistance: a reexamination. Diabetes 49:677-683

29. Blaak EE, Van Baak MA, Kemerink GJ, Pakbiers MT, Heidendal GA, Saris WH (1994) beta-Adrenergic stimulation of skeletal muscle metabolism in relation to weight reduction in obese men. Am J Physiol 267:E316-E322
30. Hulver MW, Berggren JR, Cortright RN et al. (2003) Skeletal muscle lipid metabolism with obesity. Am J Physiol Endocrinol Metab 284:E741-E747

31. Guo Z, Jensen MD (1999) Blood glycerol is an important precursor for intramuscular triacylglycerol synthesis. J Biol Chem 274:23702-23706

32. Sjostrand M, Gudbjornsdottir S, Holmang A, Strindberg L, Ekberg K, Lonnroth P (2002) Measurements of interstitial muscle glycerol in normal and insulin-resistant subjects. J Clin Endocrinol Metab 87:2206-2211

33. Hagstrom-Toft E, Qvisth V, Nennesmo I et al. (2002) Marked heterogeneity of human skeletal muscle lipolysis at rest. Diabetes 51:3376-3383

34. Rico-Sanz J, Hajnal JV, Thomas EL, Mierisova S, Ala-Korpela M, Bell JD (1998) Intracellular and extracellular skeletal muscle triglyceride metabolism during alternating intensity exercise in humans. J Physiol 510:615622

35. Hwang JH, Pan JW, Heydari S, Hetherington HP, Stein DT (2001) Regional differences in intramyocellular lipids in humans observed by in vivo $1 \mathrm{H}-\mathrm{MR}$ spectroscopic imaging. J Appl Physiol 90:1267-1274

36. Laakso M, Edelman SV, Brechtel G, Baron AD (1990) Decreased effect of insulin to stimulate skeletal muscle blood flow in obese man. A novel mechanism for insulin resistance. J Clin Invest 85:1844-1852 